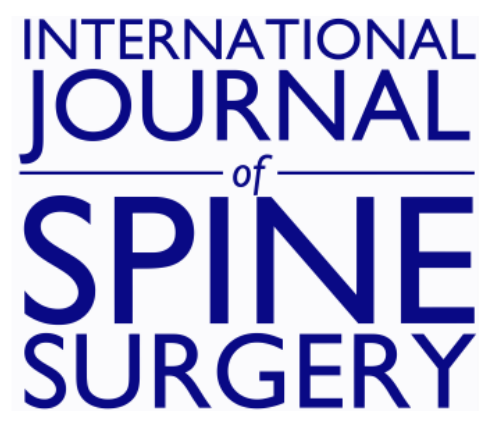

\title{
Effects of Decompressive Cervical Surgery on Blood Pressure in Cervical Spondylosis Patients With Hypertension: A Time Series Cohort Study
}

Hong Liu, Hai-Bo Wang, Lei Yue, Wei-Guo Ma, Avraam Ploumis, Ling-Ling Gao and Yang-Feng $\mathrm{Wu}$

Int J Spine Surg 2021, 15 (4) 683-691

doi: https://doi.org/10.14444/8090

http://ijssurgery.com/content/15/4/683

This information is current as of April 26, 2023.

Email Alerts Receive free email-alerts when new articles cite this article. Sign up at:

http://ijssurgery.com/alerts

The International Journal of Spine Surgery

2397 Waterbury Circle, Suite 1,

Aurora, IL 60504, Phone: +1-630-375-1432 


\title{
Effects of Decompressive Cervical Surgery on Blood Pressure in Cervical Spondylosis Patients With Hypertension: A Time Series Cohort Study
}

\author{
HONG LIU, MD ${ }^{1}$ HAI-BO WANG, PhD, ${ }^{2}$ LEI YUE, MD,${ }^{1}$ WEI-GUO MA, MD, PhD,${ }^{3,4}$ AVRAAM PLOUMIS, \\ $\mathrm{MD}, \mathrm{PhD},{ }^{5}$ LING-LING GAO, PhD ${ }^{2}$ YANG-FENG WU, $\mathrm{PhD}^{2}$ \\ ${ }^{I}$ Department of Orthopedic Surgery, Peking University First Hospital, Beijing, China, ${ }^{2}$ Peking University Clinical Research Institute, Peking University First \\ Hospital, Beijing, China, ${ }^{3}$ Department of Cardiac Surgery, Beijing Anzhen Hospital, Beijing, China, ${ }^{4}$ Aortic Institute at Yale-New Haven, Yale School of \\ Medicine, New Haven, CT, ${ }^{5}$ Division of Orthopedics and Rehabilitation, Department of Surgery, University of Ioannina Medical School, Ioannina, Greece
}

\begin{abstract}
Background: The blood pressure of cervical spondylosis (CS) patients with hypertension often returns to normal after decompressive cervical surgery (DCS). However, the effect of DCS on the blood pressure of patients with CS has not been rigorously studied.

Methods: We recruited 50 consecutive CS patients with hypertension from 2014-2017 and investigated the changes in blood pressure after DCS using a time series design. Ambulatory blood pressure monitoring (ABPM) was performed at 3 and 0 days before DCS and at 30 and 90 days after DCS. The primary outcome was mean 24-hour systolic blood pressure (SBP). Secondary outcomes included mean 24-hour diastolic blood pressure (DBP), office blood pressure, and the percentage of patients on antihypertensive medication. Paired $t$ test was used for assessing the changes in blood pressure over time and a McNemar test was used for comparison among different medication groups.

Results: The mean 24-hour SBP did not vary significantly among 4 time points $(134.5 \pm 14.7,132.8 \pm 14.7,131.5$ \pm 13.3 , and $133.2 \pm 14.6$, respectively; $P=.42$ ). The mean 24-hour DBP showed a similar trend. However, mean office SBP/DBP decreased significantly from $142.5 / 82.0 \mathrm{~mm} \mathrm{Hg}$ before surgery to $127.3 / 76.6 \mathrm{~mm} \mathrm{Hg}$ after surgery (both $P<$ $.01)$. The corresponding percentage of patients on antihypertensive medication decreased significantly, from $84 \%$ to $54 \%(P<.01)$.

Conclusions: This study confirmed previous findings of reduction in office blood pressure associated with DCS among CS patients with hypertension. However, this was not confirmed by multiple-time series of 24-hour ABPM.

Level of Evidence: 3.
\end{abstract}

Cervical Spine

Keywords: hypertension, treatment, decompressive cervical surgery, ambulatory blood pressure monitoring

\section{INTRODUCTION}

Hypertension is the leading cause of cardiovascular mortality globally, affecting over 1 billion people and causing 7.6 million deaths annually worldwide. ${ }^{1,2}$ Despite many effective pharmaceutical and nonpharmaceutical treatments available, the control of hypertension still remains unsatisfactory across the globe. Therefore, studies that shed light on the causes and possible mechanisms of hypertension will potentially lead to discovery of new ways to improve the control of this disease.

Among the possible mechanisms, sympathetic activation has been shown to be a major contributor in the development and progression of hypertension. ${ }^{3,4}$ Rich sympathetic innervation was found in cervical spinal tissues including cervical dura mater and posterior longitudinal ligament, ${ }^{5-8}$ and a study ${ }^{9}$ showed that electric stimulation of the tissue around the cervical vertebral column could increase blood pressure. Theoretically, hypertension is caused by cardiac output and/or increased peripheral resistance, whereas hyperactivity of the sympathetic nervous system is increasingly believed to be one of the mechanisms affecting cardiac output and peripheral resistance. ${ }^{3,10}$ Compression or irritation of the posterior longitudinal ligament and/or dura mater in cervical spondylosis (CS), where sympathetic nerve fibers are much denser, may lead to sympathetic hyperactivity. ${ }^{11}$ Therefore, decompressive cervical surgery (DCS), which relieves or obviates the compression or irritation to the sympathetic nervous system, would lead to a decline 
in sympathetic hyperactivity, and, consequently, reduction in blood pressure.

As early as 1962, Marin reported the association between hypertension and CS. ${ }^{12}$ This was echoed in recent studies that observed a significant decrease of office blood pressure after DCS. ${ }^{13-16}$ In our own clinical practice, we also found that blood pressure became stable or decreased considerably after DCS in many CS patients with concomitant hypertension or unstable blood pressure. In 2012, Liu and Ploumis ${ }^{17}$ proposed the concept of cervicogenic hypertension to describe this phenomenon, based on their assumption that hypertension may result from compression or stimulation of the sympathetic nervous system other than the vertebral artery. ${ }^{18}$

Although a few studies have reported the blood pressure reduction after DCS and the phenomenon is theoretically sound, reliable evidence for a causal relationship is still lacking. Most previous studies adopted the "before-after" design and took office blood pressure as the primary outcome, which is usually susceptible to biases resulting from the placebo effect and the regression-to-the-mean effect.

To avoid such biases, we used a prospective time series cohort design in the present study and used ambulatory blood pressure monitoring (ABPM) to investigate the changes in blood pressure at multiple time points before and after DCS to determine whether DCS had any impact on the blood pressure in CS patients with hypertension.

\section{METHODS}

\section{Study Design and Patient Enrollment}

The Institutional Review Board of Peking University First Hospital approved the study protocols, and written informed consent was obtained from all participants. The study was registered at ClinicalTtrials.gov (ClinicalTrials.gov Identifier: NCT02016768). Participant selection and the design of the study have been described in detail previously. ${ }^{19}$ In brief, a time series cohort study design was used to determine the effects of DCS on blood pressure in CS patients with hypertension.

Between August 2014 and September 2017, a total of 50 consecutive patients who met the following inclusion were recruited and enrolled at the Department of Orthopedics at Peking University First Hospital.

To be eligible, the patient had to meet all of the following criteria: (1) older than 18 years of age; (2) diagnosed as having CS; (3) a history of hypertension or an office systolic blood pressure (SBP) of $\geq 140 \mathrm{~mm} \mathrm{Hg}$; (4) spinal neurological symptoms lasting for at least 2 months or deteriorating despite conservative treatment; and (5) obvious signs of compression to the cervical spinal cord or nerve root detected by magnetic resonance imaging (MRI).

The lifestyle of the enrolled patients remained unchanged during this study, and no lifestyle modification was made during the follow-up period.

\section{Surgical Techniques}

Two techniques were used for cervical decompressive surgery. The anterior cervical discectomy and fusion (ACDF; ie, the Smith-Robinson technique) involves intervertebral disc incision and removal, followed by fusion with implantation of cervical interbody fusion polyetheretherketone (PEEK) cages (Solis; Stryker, Cestas, France) packed with demineralized bone matrix (BaiAo; ShanXi, China). The posterior approach was used for posterior bilateral open-door laminoplasty (ie, the modified Hemo anchored method). The anterior approach was indicated in patients with fewer than 3 levels of disc herniation, and the posterior approach was used in those with multilevel cervical spinal stenosis and continuous or mixed ossification of posterior longitudinal ligament (OPLL). The surgical levels were from $\mathrm{C} 3-\mathrm{C} 4$ to $\mathrm{C} 6-\mathrm{C} 7$, which were determined by spinal cord compression as shown on MRI scans and the nerve roots affected based on neurological findings.

\section{Imaging and Neurophysiologic Evaluation}

Plain radiographs and flexion-extension films were taken preoperatively and at 1 and 3 months after surgery. Patients were also evaluated with MRI preoperatively and at 3 months postoperatively (Figure 1). In some patients, somatosensory evoked potentials and motor evoked potentials were performed before surgery to differentiate this condition from neurologic diseases such as amyotrophic lateral sclerosis.

\section{Data Collection and Study Outcomes}

The primary outcome was SBP measured by 24hour ABPM. Secondary outcomes included diastolic blood pressure (DBP) measured by 24-hour ABPM, office blood pressure (both systolic and diastolic), the number (percentage) of patients stopping or reducing antihypertension medications, 


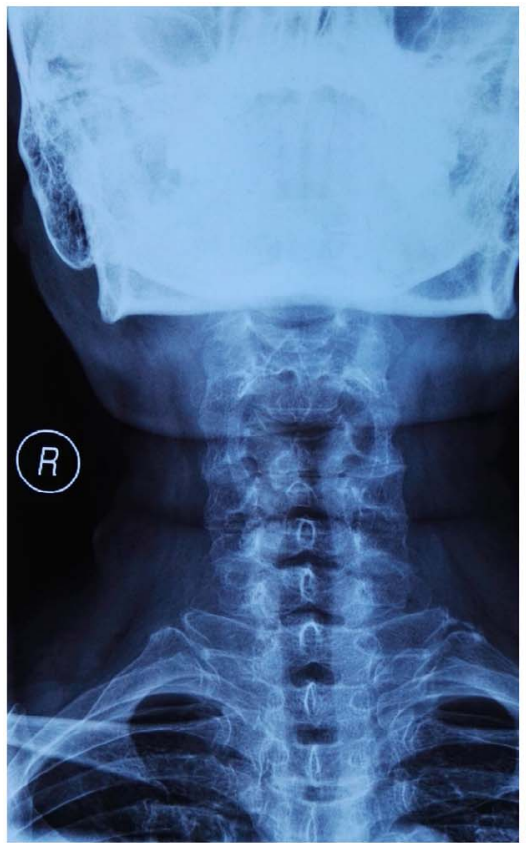

a

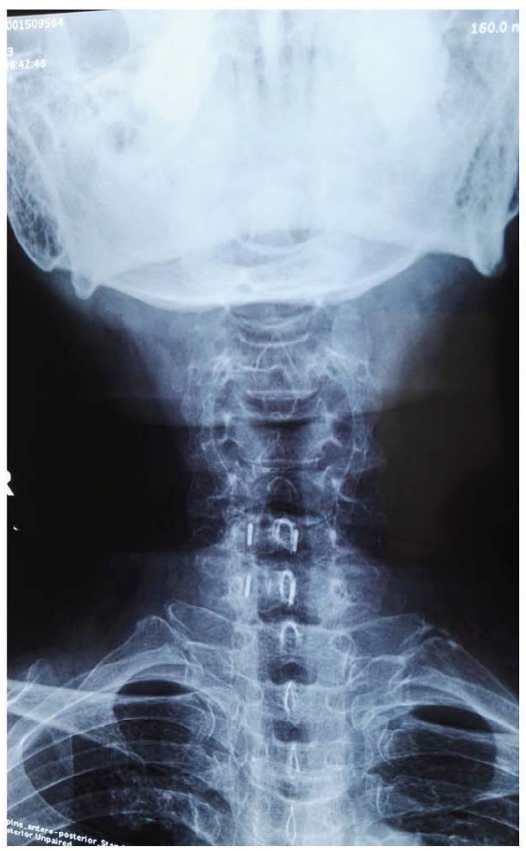

d

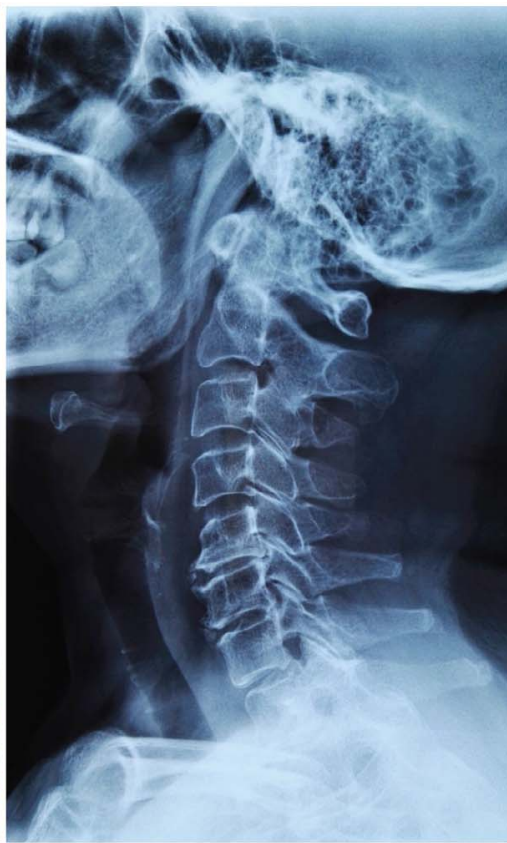

b

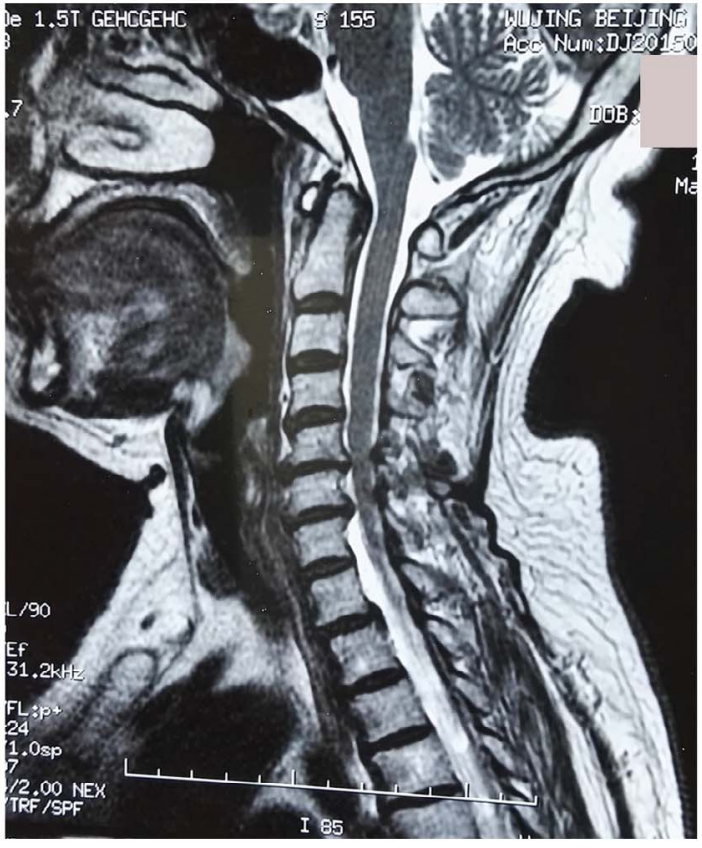

C

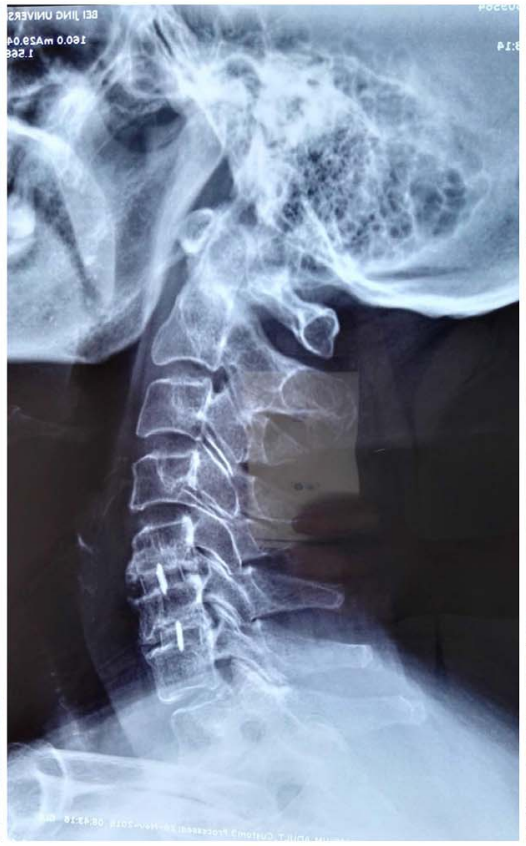

e

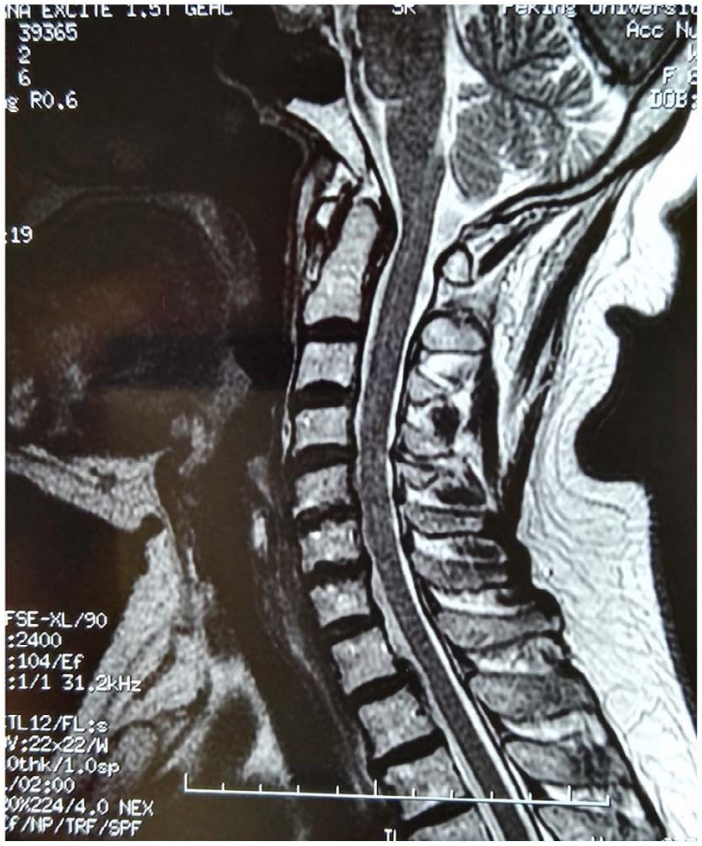

f

Figure 1. A 63-year-old woman presented with bilateral arm numbness, hand clumsiness, and gait disturbance. (a, b) Preoperative radiographs showing degeneration of C5-C7 segments. (c) Preoperative sagittal T2W1 MR image revealing spinal cord compression at levels of C5-6 and C6-7. (d, e) Plain radiographs at 3 months demonstrating adequate cervical lordosis and the implanted cage. (f) Sagittal T2W1 MR image at 1 year after ACDF showing no spinal cord compression. ACDF, anterior cervical discectomy and fusion.

and the number (percentage) of patients with satisfactory blood pressure control.

The 24-hour ABPM was performed twice, at least 3 days apart, prior to DCS. The ABPM was performed at 30 and 90 days after DCS. The 24- hour ABPM was performed using the Oscar 2 ABPM monitor (SunTech Medical, Morrisville, NC). Readings were taken every 15 minutes in the daytime and every 30 minutes at nighttime, and the overall 24-hour average for every patient in the 
department of cardiology was calculated by a technician who was blinded to the study design and purposes. Office blood pressure was measured at 3 days prior to surgery and 30 and 90 days postoperatively, but not at day 0 (the day of surgery), by experienced medical staff with an automatic oscillometric Omron HBP-1300 monitor (Omron Healthcare, Dalian, China). Blood pressure was measured with the patient in sitting position after a 5-minute rest. Three consecutive readings were taken. If the difference between readings was $>10 \mathrm{~mm} \mathrm{Hg}$, further measurements were taken to obtain 3 consecutive consistent readings. The average of these 3 readings was recorded. The use of antihypertensive medication and adverse events were recorded by the same physician at all times of data collection. Control of blood pressure was defined as a SBP of $<140 \mathrm{~mm} \mathrm{Hg}$ and a DBP of $<90 \mathrm{~mm} \mathrm{Hg}$, or as a reduction in SBP of $>20 \mathrm{~mm}$ $\mathrm{Hg}$ and DBP of $>5 \mathrm{~mm} \mathrm{Hg}$.

\section{Sample Size Estimation}

As described in the protocol, ${ }^{19}$ a sample size with 50 participants allowed for detecting a $11-\mathrm{mm} \mathrm{Hg}$ difference in 24-hour SBP before and after surgery, with at least $90 \%$ power, assuming an $\alpha$ level of .01 and a drop-out rate of $20 \% .^{20}$

\section{Statistical Analysis}

Statistical analyses were conducted using SAS version 9.4 (SAS Institute, Cary, NC). Continuous variables were expressed as mean \pm standard deviation (SD) for normally distributed data or median (interquartile range) for abnormally distributed data. Categorical variables were reported as number (percentage).

For primary outcome analyses, we first observed the variation in mean 24-hour ambulatory SBP with the 4 time points of measurement, in relation to the time of DCS. We compared the mean of two 24-hour ambulatory SBP measurements at 3 days before surgery and the day of surgery (day 0 ) with that of two 24-hour ambulatory SBP measurements at 30 and 90 days postoperatively using paired $t$ tests. The same analyses were repeated for 24-hour ABPM DBP as well as for daytime (6:00 AM-10:00 PM) and nighttime (10:00 PM-6:00 AM) 24-hour ABPM.

We further stratified the analyses according to the status of antihypertensive medication taken during the study: never had medication, medication terminated or reduced, and medication unchanged. A
Table 1. Preoperative patient profile.

\begin{tabular}{lc}
\hline Variable & Value \\
\hline Age, mean $\pm \mathrm{SD}, \mathrm{y}$ & $64.0 \pm 11.5$ \\
Male gender, $\mathrm{n}(\%)$ & $24(48)$ \\
Body mass index, mean $\pm \mathrm{SD}, \mathrm{kg} / \mathrm{m}^{2}$ & $25.0 \pm 3.5$ \\
Antihypertensive medication, $\mathrm{n}(\%)$ & $42(84)$ \\
Clinical type, n (\%) & $43(86)$ \\
Myelopathy & $31(62)$ \\
Sympathetic type & $5(10)$ \\
Radiculopathy & $36(72)$ \\
Cause of spinal compression, n $(\%)$ & $12(24)$ \\
Cervical spinal stenosis & $2(4)$ \\
Cervical disc herniation & \\
Ossification of posterior longitudinal ligament & $1.3 \pm 1.3$ \\
Severity of symptoms scale, mean \pm SD & $11.3 \pm 3.3$ \\
Visual analog scale score & \\
Japanese Orthopedic Association score & \\
\hline
\end{tabular}

separate subgroup analysis was performed of "true" versus "white-coat" hypertension, which was defined as an office blood pressure of $\geq 140 / 90 \mathrm{~mm} \mathrm{Hg}$ with daytime ambulatory $\mathrm{BP}$ of $<135 / 85 \mathrm{~mm} \mathrm{Hg}$. A $t$ test was used to compare the changes in blood pressure after surgery among groups with different medication statuses and with true versus white-coat hypertension. The rate of blood pressure control and the change in antihypertensive medication were compared using the McNemar test. All statistical tests were 2 -sided and a $P$ value of $<.05$ was considered statistically significant.

\section{RESULTS}

\section{Baseline Characteristics}

Mean age was $64.0 \pm 11.5$ years (range, 37-82 years), and $52 \%$ of patients were women. Participants included 36 patients with cervical spinal stenosis, 12 with disc herniation, and 2 with OPLL. Myelopathy was the most common (86\%), followed by sympathetic type (CS with sympathetic symptoms, $62.0 \%)$ and radiculopathy $(10 \%)$. The Japanese Orthopedic Association (JOA) and visual analog scale (VAS) scores were $1.3 \pm 1.3$ and 11.3 \pm 3.3 on average, respectively. Laminoplasty was performed in 36 patients and 14 patients underwent ACDF, including single level in 7, two levels in 3 and three levels in 7 patients, respectively (Table 1).

All participants completed the follow-up at 1 month postoperatively. Two patients were lost to follow-up at 3 months.

\section{Ambulatory and Office Blood Pressure Measurements}

As shown in Table 2 and Figure 2, the mean 24hour ambulatory SBP did not vary much among the 
Table 2. Changes in blood pressure measurement, medication, and rate of control. ${ }^{\mathrm{a}}$

\begin{tabular}{|c|c|c|c|c|c|c|}
\hline \multirow[b]{2}{*}{ Variable } & \multirow[b]{2}{*}{ Before Surgery } & \multicolumn{3}{|c|}{ After Surgery } & \multirow[b]{2}{*}{ Change After Surgery } & \multirow[b]{2}{*}{$P$ Value } \\
\hline & & Day 30 & Day 90 & Average & & \\
\hline \multicolumn{7}{|l|}{ Ambulatory $\mathrm{BP}^{\mathrm{b}}$} \\
\hline \multicolumn{7}{|l|}{24 hours } \\
\hline Systolic BP & $133.7 \pm 12.5$ & $131.5 \pm 13.3$ & $133.2 \pm 14.6$ & $132.3 \pm 12.7$ & $1.4 \pm 11.6$ & .42 \\
\hline Diastolic BP & $77.0 \pm 9.7$ & $76.5 \pm 8.7$ & $76.2 \pm 9.4$ & $76.4 \pm 8.5$ & $0.5 \pm 5.7$ & .52 \\
\hline \multicolumn{7}{|l|}{ Daytime } \\
\hline Systolic & $135.5 \pm 12.7$ & $133.0 \pm 13.3$ & $134.6 \pm 14.4$ & $133.8 \pm 12.6$ & $1.7 \pm 11.9$ & .31 \\
\hline Diastolic & $78.4 \pm 9.9$ & $77.7 \pm 9.0$ & $77.7 \pm 9.6$ & $77.8 \pm 8.8$ & $0.6 \pm 6.1$ & .47 \\
\hline \multicolumn{7}{|l|}{ Nighttime } \\
\hline Systolic & $127.2 \pm 14.9$ & $125.5 \pm 16.1$ & $128.0 \pm 19.4$ & $126.8 \pm 15.1$ & $0.5 \pm 14.9$ & .83 \\
\hline Diastolic & $71.7 \pm 10.4$ & $71.7 \pm 9.2$ & $70.9 \pm 11.4$ & $71.4 \pm 9.2$ & $0.3 \pm 7.4$ & .71 \\
\hline \multicolumn{7}{|l|}{ Office $\mathrm{BP}^{\mathrm{b}}$} \\
\hline Systolic & $142.5 \pm 17.1$ & $127.5 \pm 7.8$ & $126.9 \pm 8.1$ & $127.3 \pm 6.5$ & $15.3 \pm 15.9$ & $<.001$ \\
\hline Diastolic & $82.0 \pm 8.6$ & $77.4 \pm 5.5$ & $75.9 \pm 4.8$ & $76.6 \pm 4.2$ & $5.5 \pm 8.7$ & $<.001$ \\
\hline \multicolumn{7}{|l|}{ Medication and control $^{c}$} \\
\hline On medication, n (\%) & $42(84)$ & $28(56)$ & $26(54.2)^{\mathrm{d}}$ & $\ldots$ & $\ldots$ & $<.001$ \\
\hline Dose reduction, $\mathrm{n}(\%)^{\mathrm{e}}$ & & $22(52.4)$ & $25(62.5)$ & $\ldots$ & $\ldots$ & $\ldots$ \\
\hline Rate of control, n (\%) & $35(70)$ & $40(80)$ & $34(70.8)^{\mathrm{d}}$ & $\ldots$ & $\ldots$ & 1.00 \\
\hline
\end{tabular}

Abbreviations: ABPM, ambulatory blood pressure monitoring; BP, blood pressure.

${ }^{\mathrm{a}} \mathrm{ABPM}$ before surgery: average BP was measured at day -3 and day 0 (the day of surgery); office BP before surgery: office BP was measured at day -3 , but not at day 0 ; BP after surgery: average ambulatory and office BP were measured at days 30 and 90.

${ }^{\mathrm{b}}$ Paired $t$ tests for comparing the differences in ambulatory and office blood pressure after surgery.

${ }^{\mathrm{c}} \mathrm{McNemar}$ test for comparing medication and rate of control.

${ }^{\mathrm{d}}$ Two patients were lost to follow-up at 90 days.

${ }^{\mathrm{e}}$ The denominator was 42 patients who were on anti-hypertensive medications before surgery.

4 time points; neither did the average 24-hour ambulatory SBP differ between the 2 times before DCS and the 2 time points after DCS $(P=.42)$. Nor did the 24-hour ambulatory DBP or the daytime and nighttime SBP or DBP differ significantly before and after DCS (all $P>.05$ ).

However, both office SBP and DBP at 30 and 90 days postoperatively were significantly lower than baseline measurements $(P<.001$; Table 2). The

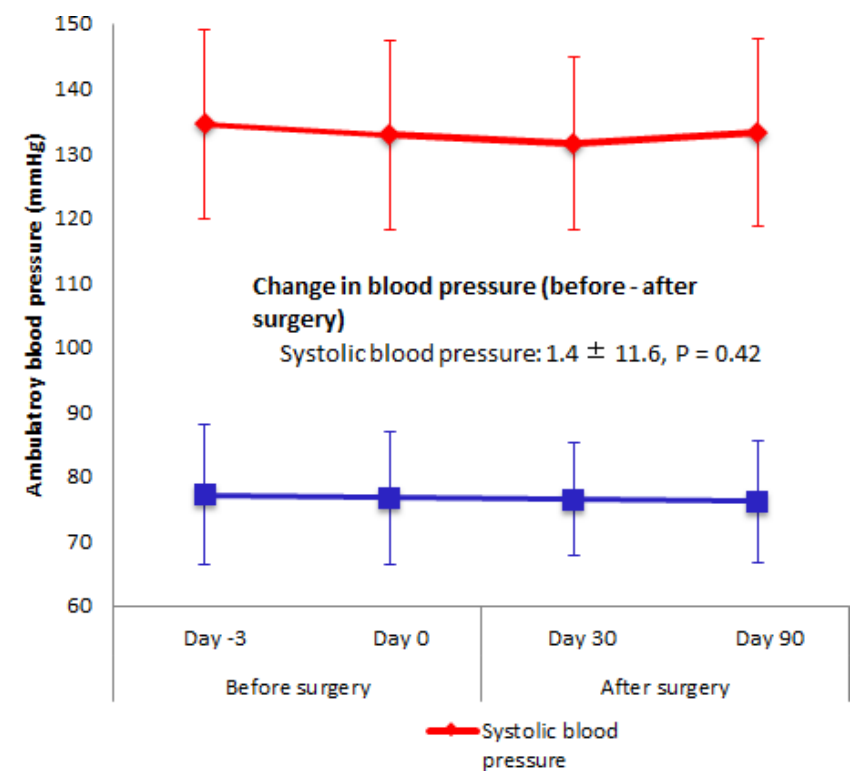

Figure 2. Ambulatory blood pressure before and after surgery. Change in blood pressure (before-after surgery) $=$ average preoperative blood pressure (days -3 and 0) - average postoperative blood pressure (days 30 and 90). Difference in blood pressure before and after surgery was compared with paired $t$ tests. percentage of patients on antihypertensive medication decreased significantly after DCS ( $56 \%$ vs $84 \%$, $P<.001)$, whereas the rate of blood pressure control remained unchanged after DCS $(70.8 \%$ vs $70.0 \%, P=1.00)$.

\section{Blood Pressure Change Stratified by Antihypertensive Medication Groups}

During the study period, 8 participants $(16 \%)$ never had any medication, $22(44 \%)$ had a reduction, and the medication was unchanged for $20(40 \%)$. The before-after changes in 24-hour ambulatory SBP/DBP after DCS were minor and not significant in any of the 3 subgroups (all $P>$ .05 ; Table 3). However, all 3 medication groups experienced a significant change in office $\mathrm{SBP} / \mathrm{DBP}$ (all $P<.01$ ), except the DBP among patients who experienced a dose reduction $(P=.29)$.

Compared with those with medication cessation or dose reduction, participants who never had any medication or whose medication had not changed experienced a significant decrease in their office SBP $(P=.004)$ and DBP $(P=.03)$. However, the differences in the 24-hour and the daytime and nighttime SBP/DBP on 24-hour ambulatory monitoring were not significant (Table 3).

\section{Blood Pressure Change Stratified by Clinical Types}

As shown in Table 4, the changes in 24-hour ambulatory SBP/DBP after DCS were not signifi- 
Table 3. Changes in blood pressure from baseline stratified by antihypertensive medication. ${ }^{a}$

\begin{tabular}{|c|c|c|c|c|c|c|c|}
\hline \multirow{2}{*}{$\begin{array}{l}\text { Blood Pressure } \\
\text { Measurements }\end{array}$} & \multirow{2}{*}{$\begin{array}{l}\text { Antihypertensive } \\
\text { Medication }\end{array}$} & \multirow[b]{2}{*}{ No. of Patients } & \multirow[b]{2}{*}{ Baseline BP } & \multicolumn{3}{|c|}{ Changes of BP From Baseline } & \multirow[b]{2}{*}{$P$ Value } \\
\hline & & & & at $1 \mathrm{mo}$ & at $3 \mathrm{mo}$ & Average & \\
\hline \multicolumn{8}{|l|}{ АВPM } \\
\hline \multirow[t]{3}{*}{ Systolic } & Dose reduced & 22 & $131.2 \pm 12.4$ & $-1.1 \pm 14.6$ & $0.3 \pm 15.7$ & $-0.4 \pm 13.7$ & .900 \\
\hline & Medication unchanged & 20 & $137.8 \pm 12.7$ & $-2.4 \pm 11.7$ & $-2.3 \pm 10.1$ & $-2.3 \pm 9.8$ & .310 \\
\hline & $\begin{array}{l}\text { No medication } \\
P \text { value }\end{array}$ & 8 & $\begin{array}{c}130.0 \pm \\
.45\end{array}$ & $-4.9 \pm 10.0$ & $\begin{array}{c}1.6 \pm 13.8 \\
.79\end{array}$ & $-1.6 \pm 10.8$ & .690 \\
\hline \multirow[t]{4}{*}{ Diastolic } & Dose reduced & 22 & $76.9 \pm 7.9$ & $0.3 \pm 7.7$ & $-0.2 \pm 8.3$ & $0.02 \pm 6.9$ & .990 \\
\hline & Medication unchanged & 20 & $77.2 \pm 11.2$ & $-1.4 \pm 4.5$ & $-0.9 \pm 5.8$ & $-1.3 \pm 4.4$ & .200 \\
\hline & No medication & 8 & $76.5 \pm 11.4$ & $-0.3 \pm 4.1$ & $0.3 \pm 7.1$ & $-0.01 \pm 5.4$ & 1.000 \\
\hline & $P$ value ${ }^{\mathrm{bc}}$ & & .96 & .46 & .88 & .55 & \\
\hline \multicolumn{8}{|l|}{ Office BP } \\
\hline \multirow[t]{3}{*}{ Systolic } & Dose reduced & 22 & $135.1 \pm 12.9$ & $-7.7 \pm 14.4$ & $-8.4 \pm 14.4$ & $-8.0 \pm 13.1$ & .010 \\
\hline & Medication unchanged & 20 & $151.6 \pm 20.1$ & $-23.5 \pm 19.3$ & $-25.3 \pm 16.9$ & $-23.5 \pm 17.9$ & $<.001$ \\
\hline & $\begin{array}{l}\text { No medication } \\
P \text { value }\end{array}$ & 8 & $\begin{array}{c}130.5 \pm 4.6 \\
.006\end{array}$ & $\begin{array}{c}-4.9 \pm 2.5 \\
.007\end{array}$ & $\begin{array}{c}-5.3 \pm 3.0 \\
.002\end{array}$ & $-5.1 \pm 1.7$ & $<.001$ \\
\hline \multirow[t]{4}{*}{ Diastolic } & Dose reduced & 22 & $79.8 \pm 7.8$ & $-1.1 \pm 9.3$ & $-2.9 \pm 9.1$ & $-2.0 \pm 8.6$ & .290 \\
\hline & Medication unchanged & 20 & $84.6 \pm 9.1$ & $-8.5 \pm 8.7$ & $-9.8 \pm 10.6$ & $-9.2 \pm 8.8$ & $<.001$ \\
\hline & No medication & 8 & $78.3 \pm 5.3$ & $-1.8 \pm 2.5$ & $-2.9 \pm 3.5$ & $-2.3 \pm 2.4$ & .030 \\
\hline & $P$ value & & .13 & .01 & .08 & .03 & \\
\hline
\end{tabular}

Abbreviations: ABPM, ambulatory blood pressure monitoring; BP, blood pressure.

${ }^{a}$ Blood pressure values are expressed as mean \pm standard deviation.

${ }^{\mathrm{b}}$ These four $P$ values refer to comparison of dose reduction group to those with unchanged or no medication.

${ }^{\mathrm{c}}$ Paired $t$-test for comparing the difference in blood pressure after surgery; $\S t$-test for comparison of three medication groups.

cant in the 3 clinical types of CS. However, changes in the office SBP/DBP were significant in the myelopathy and sympathetic subgroups; it was not significant, however, in the radiculopathy subgroup.

\section{Changes in Blood Pressure With True Versus White-Coat Hypertension}

Of the 50 participants in this study, 20 were categorized as white-coat hypertension at baseline. The 24-hour ambulatory SBP increased by about 4 $\mathrm{mm} \mathrm{Hg}$ after DCS in participants with white-coat hypertension, whereas those with true hypertension experienced a decrease of $3 \mathrm{~mm} \mathrm{Hg}$ in ambulatory
SBP. On the contrary, the office SBP decreased significantly after DCS in participants with whitecoat $(P<.001)$ and true hypertension $(P=.001)$ for a similar magnitude of 5-6 $\mathrm{mm} \mathrm{Hg}$. The same trend was observed in the changes of office DBP with white-coat $(P=.002)$ and true hypertension $(P=$ .019 ; Table 5).

\section{Severity of Clinical Symptoms and Postoperative Adverse Events}

A total of 5 postoperative adverse events occurred in 3 participants, including hematoma formation, cerebrospinal fluid leakage, acute myo-

Table 4. Changes in blood pressure stratified by clinical types of cervical spondylosis. ${ }^{a}$

\begin{tabular}{|c|c|c|c|c|c|c|c|}
\hline \multirow[b]{2}{*}{ Blood Pressure } & \multirow[b]{2}{*}{ Clinical Types } & \multirow[b]{2}{*}{ No. of Patients } & \multirow[b]{2}{*}{ Baseline BP } & \multicolumn{2}{|c|}{ At $1 \mathrm{mo}$} & \multicolumn{2}{|c|}{ At $3 \mathrm{mo}$} \\
\hline & & & & Difference & $P$ Value $^{\text {b }}$ & Difference & $P$ Value $^{b}$ \\
\hline \multicolumn{8}{|c|}{ 24-hour ambulatory BP } \\
\hline \multirow[t]{3}{*}{ Systolic } & Myelopathy & 43 & $132.1 \pm 11.15$ & $-1.53 \pm 12.94$ & .444 & $0.40 \pm 13.24$ & .842 \\
\hline & Sympathetic type & 31 & $133.4 \pm 13.55$ & $-2.04 \pm 12.36$ & .366 & $-1.18 \pm 12.14$ & .594 \\
\hline & Radiculopathy & 5 & $134.2 \pm 11.11$ & $-6.10 \pm 7.95$ & .161 & $-0.97 \pm 13.45$ & .879 \\
\hline \multirow[t]{3}{*}{ Diastolic } & Myelopathy & 43 & $75.6 \pm 9.06$ & $-0.36 \pm 6.18$ & .707 & $0.01 \pm 7.12$ & .991 \\
\hline & Sympathetic type & 31 & $78.3 \pm 10.44$ & $-0.07 \pm 5.31$ & .941 & $-0.84 \pm 6.54$ & .497 \\
\hline & Radiculopathy & 5 & $80.5 \pm 12.48$ & $-1.57 \pm 4.75$ & .501 & $-0.35 \pm 7.51$ & .923 \\
\hline \multicolumn{8}{|c|}{ Office blood pressure } \\
\hline \multirow[t]{3}{*}{ Systolic } & Myelopathy & 43 & $131.8 \pm 9.02$ & $-5.31 \pm 7.08$ & $<.001$ & $-5.39 \pm 6.77$ & $<.001$ \\
\hline & Sympathetic type & 31 & $131.9 \pm 9.38$ & $-4.82 \pm 5.56$ & $<.001$ & $-5.76 \pm 4.78$ & $<.001$ \\
\hline & Radiculopathy & 5 & $142.7 \pm 16.42$ & $-17.27 \pm 17.61$ & .093 & $-10.60 \pm 22.79$ & .357 \\
\hline \multirow[t]{3}{*}{ Diastolic } & Myelopathy & 43 & $78.2 \pm 4.14$ & $-1.76 \pm 3.72$ & .003 & $-2.35 \pm 4.44$ & .002 \\
\hline & Sympathetic type & 31 & $78.2 \pm 4.97$ & $-2.41 \pm 3.95$ & .002 & $-3.21 \pm 4.52$ & $<.001$ \\
\hline & Radiculopathy & 5 & $82.9 \pm 10.67$ & $-5.67 \pm 9.77$ & .264 & $-6.20 \pm 11.32$ & .288 \\
\hline
\end{tabular}

Abbreviation: BP, blood pressure.

${ }^{a}$ Blood pressure values are expressed as mean \pm standard deviation.

${ }^{\mathrm{b}} P$ values denote the comparison of postoperative blood pressure to baseline values. Paired $t$ test was used to compare the difference in blood pressure after surgery. 
Table 5. Changes in blood pressure with true or white-coat hypertension.

\begin{tabular}{|c|c|c|c|c|c|c|c|}
\hline \multirow[b]{2}{*}{ Blood Pressure $^{a}$} & \multirow[b]{2}{*}{ True or White-Coat HTN $^{b}$} & \multirow[b]{2}{*}{$\mathbf{N}$} & \multirow[b]{2}{*}{ Baseline BP } & \multicolumn{2}{|c|}{ At $1 \mathrm{mo}$} & \multicolumn{2}{|c|}{ At 3 mo } \\
\hline & & & & Difference $^{c}$ & $P$ Value $^{\mathrm{d}}$ & Difference $^{c}$ & $P$ Value $^{\text {d }}$ \\
\hline \multicolumn{8}{|l|}{ АВРM } \\
\hline \multirow[t]{2}{*}{ Systolic } & True & 30 & $140.9 \pm 10.26$ & $-6.25 \pm 12.25$ & .009 & $-3.12 \pm 14.35$ & .251 \\
\hline & White-coat & 20 & $122.9 \pm 6.15$ & $3.91 \pm 10.98$ & .090 & $4.05 \pm 10.68$ & .115 \\
\hline \multirow[t]{2}{*}{ Diastolic } & True & 30 & $81.1 \pm 9.26$ & $-2.53 \pm 5.49$ & .017 & $-1.91 \pm 7.17$ & .163 \\
\hline & White-coat & 20 & $70.7 \pm 6.53$ & $2.59 \pm 5.48$ & .076 & $1.89 \pm 6.55$ & .225 \\
\hline \multicolumn{8}{|l|}{ Office BP } \\
\hline \multirow[t]{2}{*}{ Systolic } & True & 30 & $133.6 \pm 10.08$ & $-5.41 \pm 7.29$ & $<.001$ & $-4.78 \pm 7.20$ & .001 \\
\hline & White-coat & 20 & $130.7 \pm 6.09$ & $-5.26 \pm 5.70$ & $<.001$ & $-6.42 \pm 7.02$ & $<.001$ \\
\hline \multirow[t]{2}{*}{ Diastolic } & True & 30 & $79.6 \pm 4.92$ & $-1.54 \pm 3.80$ & .035 & $-2.31 \pm 5.00$ & .019 \\
\hline & White-coat & 20 & $77.2 \pm 3.15$ & $-1.71 \pm 3.66$ & .050 & $-3.23 \pm 4.00$ & .002 \\
\hline
\end{tabular}

Abbreviations: ABPM, ambulatory blood pressure monitoring; BP, blood pressure; HTN, hypertension; N, number of patients

${ }^{\mathrm{a} B}$ Blood pressure values are expressed as mean \pm standard deviation.

${ }^{\mathrm{b}}$ In this analysis, true HTN was defined as a systolic blood pressure of $\geq 130$ and/or diastolic blood pressure of $\geq 80 \mathrm{~mm}$ Hg during 24 -hour ABPM. Other conditions were defined as "white-coat hypertension."

${ }^{c}$ Difference refers to the change from baseline blood pressure.

${ }^{\mathrm{d}}$ Paired $t$ test was used to comparing the difference in blood pressure after surgery.

cardial infarction, shingles, and laryngeal polypus. Hematoma formation and cerebrospinal fluid leakage were determined to be related to the surgical procedure.

Of the whole series, at 90 days after surgery, the VAS score decreased (0.8 vs $1.3, P=.004)$ and the JOA score increased (14.4 vs 11.3, $P<.001)$, respectively, which was statistically significant.

\section{DISCUSSION}

To the best of our knowledge, this study may be the first one adopting time series cohort design to prospectively assess the causal relationship between DCS and subsequent blood pressure reduction among CS patients with hypertension using ABPM. Because surgery is the treatment of choice for patients with CS, it is unethical to conduct randomized controlled trials to test the hypothesis. A time series cohort study allows for observing the changes in blood pressure at multiple time points before and after surgery, which may provide evidence supporting the blood pressure-lowering effect of DCS among these patients. More importantly, we used 24-hour ABPM and blinded the observer for its measurement. No significant changes were observed in 24-hour ambulatory SBP and DBP that could be ascribed to DCS in this study.

Research into the relationship between CS and hypertension dates back to the 1960 s. ${ }^{12}$ In 1981 , Watanuki ${ }^{9}$ found that blood pressure was increased by electric stimulation of the tissue adjacent to the cervical vertebrae column. More recently, Summers and associates ${ }^{21}$ described volatile hypertension following ACDF, whereas Pan and Pan ${ }^{22}$ reported a decrease in blood pressure after chiropractic maneuvers in a small cohort of patients with CS. In 2012, Liu and Ploumis ${ }^{17}$ proposed the concept of cervicogenic hypertension, hypothesizing that CS may be a cause of essential hypertension or may represent a type of secondary hypertension.

We initiated the present study in 2013 to test whether a causal relationship existed between DCS and blood pressure reduction among CS patients with hypertension. ${ }^{19}$ Subsequently, several studies have reported the effect of DCS on concomitant hypertension. ${ }^{13-16}$ Among 144 patients with cervical myelopathy who were hypertensive before surgery, $\mathrm{Li}$ and colleagues ${ }^{13}$ observed that blood pressure returned to normal 1 week after surgery in 106 $(73.6 \%)$ patients and decreased to some extent in 37 patients $(25.7 \%)$. Peng et $\mathrm{al}^{14}$ reported 2 patients with CS sustaining vertigo and hypertension whose blood pressure dropped to the normal range after DCS, which suggested that CS may be one of the causes of secondary hypertension. Yang and colleagues ${ }^{15}$ observed a significant decrease of both SBP and DBP at 3 and 12 months following DCS in 103 patients and concluded that DCS could reduce concomitant high blood pressure in patients with cervical myelopathy. In the study of Itoh and colleagues, ${ }^{16}$ a significant blood pressure reduction at 6 months after DCS was demonstrated in the hypertension group, rather than the normotensive group, and the effect was more remarkable in patients with refractory hypertension. These studies suggest that CS may lead to hypertension and that DCS is effective in attenuating this type of hypertension.

Consistent with previous studies, the present study also observed a significant reduction in office 
blood pressure after DCS. ${ }^{13-16}$ In addition, cessation or dose reduction of antihypertensive medication was observed in $44 \%$ of participants after DCS. However, none of the favorable changes of office blood pressure observed previously and in the present study are exempt from biases secondary to the regression-to-the-mean effect or the placebo effect; these changes are not caused by the whitecoat hypertension effect, which refers to a persistently elevated blood pressure in the office but with a normal blood pressure in other settings. Hence, the findings of this study do not support a direct causal relationship between DCS and the significant decrease in office blood pressure. These results indicate that the regression-to-the-mean effect did exist in our study, even with 24-hour ABPM. This finding strengthens our judgment that the observed reduction in office blood pressure after DCS was mainly due to the regression-to-the-mean effect and the placebo effect commonly seen in all hypertension treatment studies, which appeared in the present study also, given the lack of a parallel placebo control group. In contrast, the time series cohort design with multiple measurements and use of ABPM instead of office blood pressure measurement in this study largely avoided these biases. Therefore, the results of the present study should be much more reliable.

ABPM has been increasingly used to evaluate antihypertensive effects in clinical trials, with higher predictive value for hypertension-related events. ${ }^{23-26}$ In 2011, the National Institute for Health and Clinical Excellence Guidance recommended the use of ABPM to verify the diagnosis of hypertension if office blood pressure was $\geq 140 / 90 \mathrm{~mm} \mathrm{Hg}{ }^{27}$ Pickering et $\mathrm{al}^{24}$ also suggested that ABPM may be regarded as the gold standard for the prediction of risk related to hypertension because of its reliability and accuracy. Therefore, we used ambulatory blood pressure as the primary study outcome in this study, which may be more objective and can avoid potential biases inherent to office blood pressure measurement in single-arm studies.

\section{Study Limitations}

This study has several limitations. First, as with any observational study, all possible biases could not be ruled out. Although a time series cohort design was used and the observer blinded to ABPM as a remedy, we were unable to blind the observer to office blood pressure measurement. In addition, only 1 measurement of office blood pressure was taken before DCS, which limited our ability to minimize the effect of the regression-to-the-mean on the results of office blood pressure. Second, because antihypertensive medications were not fixed in the study, which makes it less possible to determine the impact of DCS on blood pressure. However, further analysis showed that the effect of DCS on ambulatory blood pressure did not differ with the statuses of antihypertensive medication, indicating that the use of medications had no effect on the main results. Third, no marker of sympathetic nervous activity was evaluated in this study, such as catecholamine levels, which may reflect the activity of sympathetic nervous system. However, we broke down the ABPM results by day and night times, which could more or less reflect the activity of the sympathetic nervous system. Another weakness pertains to the lack of preoperative spinal imaging measurements, which precludes quantitative analysis of spinal compressions that may result in hypertension. Finally, the findings of this study should be interpreted with caution given its observational nature, small sample size, and single-center setting.

\section{Conclusions}

In this study, we did not observe a DCSassociated reduction in 24-hour ambulatory blood pressure among cervical spondylosis patients with hypertension, despite the significant decrease in office blood pressure levels and in the percentage of patients on antihypertensive medication. Further studies with a larger sample size and in multiple centers are warranted to better understand the effect of decompressive cervical surgery on the blood pressure in patients with cervical spondylosis and concomitant hypertension.

\section{ACKNOWLEDGMENTS}

Drs Hong Liu and Hai-Bo Wang are co-first authors. All authors gratefully acknowledge the assistance of Xian Su, Fei Wu, and Runyi Ma in the protocol development and project management.

\section{REFERENCES}

1. Chow CK, Teo KK, Rangarajan S, et al. Prevalence, awareness, treatment, and control of hypertension in rural and urban communities in high-, middle-, and low-income countries. JAMA. 2013;310(9):959-968.

2. Kearney PM, Whelton M, Reynolds K, Muntner P, 
Whelton PK, He J. Global burden of hypertension: analysis of worldwide data. Lancet. 2005;365(9455):217-223.

3. Lechin F, van der Dijs B. Central nervous system circuitry and peripheral neural sympathetic activity responsible for essential hypertension. Curr Neurovasc Res. 2006;3(4):307-325.

4. Grassi G, Mark A, Esler M. The sympathetic nervous system alterations in human hypertension. Circ Res. 2015;116(6):976-990.

5. Yamada H, Honda T, Yaginuma H, Kikuchi S, Sugiura Y. Comparison of sensory and sympathetic innervation of the dura mater and posterior longitudinal ligament in the cervical spine after removal of the stellate ganglion. J Comp Neurol. 2001;434(1):86-100.

6. Kiray A, Arman C, Naderi S, Guvencer M, Korman E. Surgical anatomy of the cervical sympathetic trunk. Clin Anat. 2005;18(3):179-185.

7. Saylam CY, Ozgiray E, Orhan M, Cagli S, Zileli M. Neuroanatomy of cervical sympathetic trunk: a cadaveric study. Clin Anat. 2009;22(3):324-330.

8. Li J, Gu T, Yang H, et al. Sympathetic nerve innervation in cervical posterior longitudinal ligament as a potential causative factor in cervical spondylosis with sympathetic symptoms and preliminary evidence. Med Hypotheses. 2014;82(5):631-635.

9. Watanuki A. The effect of the sympathetic nervous system on cervical spondylosis [in Japanese]. Nihon Seikeigeka Gakkai Zasshi. 1981;55(4):371-385.

10. Saxena T, Ali AO, Saxena M. Pathophysiology of essential hypertension: an update. Expert Rev Cardiovasc Ther. 2018;16(12):879-887.

11. Li J, Jiang DJ, Wang XW, Yuan W, Liang L, Wang ZC. Mid-term outcomes of anterior cervical fusion for cervical spondylosis with sympathetic symptoms. Clin Spine Surg. 2016;29(6):255-260.

12. Marin F. Contribution on the clinical aspects of cervical spondylosis. Hypertension and cerebral regional hypertension in cervical spondylosis [in Romanian]. Med Interna (Bucur). 1962;14:1505-1511.

13. Li ZQ, Zhao YP, Jia WY, et al. Surgical treatment of cervical spondylotic myelopathy associated hypertension-a retrospective study of 309 patients. PLoS One. 2015;10(7):e0133828.

14. Peng B, Pang X, Li D, Yang H. Cervical spondylosis and hypertension: a clinical study of 2 cases. Medicine (Baltimore). 2015;94(10):e618.

15. Yang L, Yang C, Pang X, et al. Cervical decompression surgery for cervical spondylotic myelopathy and concomitant hypertension: a multicenter prospective cohort study. Spine (Phila Pa 1976). 2017;42(12):903-908.

16. Itoh K, Kurokawa R, Shingo T, Kim P. Effect of myoarchitectonic spinolaminoplasty on concurrent hypertension in patients with cervical spondylotic myelopathy. Neurospine. 2018;15(1):77-85.

17. Liu H, Ploumis A. Cervicogenic hypertension-a possible etiology and pathogenesis of essential hypertension. Hypothesis. 2012;10(1):e4. doi:10.5779/hypothesis.v10i1.297

18. Liu H, Kawaguchi Y. Anterior cervical discectomy and fusion to treat cervical spondylosis with sympathetic symptoms. J Spinal Disord Tech. 2011;24(1):11-14.

19. Liu H, Wang HB, Wu L, et al. Effects of decompressive cervical surgery on blood pressure in cervical spondylosis patients with hypertension: a time series cohort study. $B M C$ Surg. 2016;16:2. doi: 10.1186/s12893-015-0117-y

20. Esler MD, Krum H, Sobotka PA, et al, Symplicity HTN2 Investigators. Renal sympathetic denervation in patients with treatment-resistant hypertension (the Symplicity HTN-2 Trial): a randomised controlled trial. Lancet. 2010;376(9756):19031909.

21. Summers SH, Sabeh K, Gottlieb J. Volatile hypertension following anterior cervical discectomy and fusion: a case report. JBJS Case Connect. 2016;6(1):e12. doi: 10.2106/JBJS.CC.O. 00154

22. Pan Z, Pan X. Cervical spondylosis and hypertension. Presented at the 12th Academic Meeting of the Cervical Spondylosis Committee of the Chinese Rehabilitation Association; June 22, 2010, Beijing.

23. Mancia G, Parati G. Office compared with ambulatory blood pressure in assessing response to antihypertensive treatment: a meta-analysis. J Hypertens. 2004;22(3):435-445.

24. Pickering TG, Shimbo D, Haas D. Ambulatory bloodpressure monitoring. N Engl J Med. 2006;354(22):2368-2374.

25. Mahfoud F, Ukena C, Schmieder RE, et al. Ambulatory blood pressure changes after renal sympathetic denervation in patients with resistant hypertension. Circulation. 2013;128(2):132-140.

26. Schmieder RE, Schmidt ST, Riemer T, et al. Disproportional decrease in office blood pressure compared with 24hour ambulatory blood pressure with antihypertensive treatment: dependency on pretreatment blood pressure levels. Hypertension. 2014;64(5):1067-1072.

27. Krause T, Lovibond K, Caulfield M, McCormack T, Williams B. Management of hypertension: summary of NICE guidance. BMJ. 2011;343:d4891.

Disclosures and COI: This research was funded by Peking University Clinical Research Program (Grant No. PUCRP201304) at Peking University Health Science Center. Excessive treatment and service support costs incurred in the research were funded by Peking University First Hospital. The authors declare no conflict of interest.

Corresponding Authors: Hong Liu, Department of Orthopedic Surgery, Peking University First Hospital, 8 Xishiku Street, Beijing 100034, China. Phone: +86 (10) 83572326; Fax: +86 (10) 66551057; Email: liuhooong@163.com. Yang-Feng Wu, Executive Associate Director, Peking University Clinical Research Institute, 38 Xueyuan Road, Beijing 100191, China. Phone/Fax: + 86 (10) 82805831; Email: wuyf@bjmu.edu.cn.

Published 19 August 2021

This manuscript is generously published free of charge by ISASS, the International Society for the Advancement of Spine Surgery. Copyright $\odot 2021$ ISASS. To see more or order reprints or permissions, see http://ijssurgery.com. 